\title{
Low-dose intravenous ketamine versus intravenous ketorolac in pain control in patients with acute renal colic in an emergency setting: a double-blind randomized clinical trial
}

\author{
Mehran Sotoodehnia, Mozhgan Farmahini-Farahani, Arash Safaie, Fatemeh Rasooli, and Alireza Baratloo \\ Prehospital Emergency Research Center and Department of Emergency Medicine, Sina Hospital, \\ Tehran University of Medical Sciences, Tehran, Iran
}

Background: This study was conducted to compare the effectiveness of low-dose ketamine versus ketorolac in pain control in patients with acute renal colic presenting to the emergency department (ED).

Methods: This is a double-blind randomized clinical trial. The initial pain severity was assessed using the numerical rating scale (NRS). Then, ketamine or ketorolac was administered intravenously at a dose of $0.6 \mathrm{mg} / \mathrm{kg}$ and $30 \mathrm{mg}$ respectively. The pain severity and adverse drug reactions were recorded 5, 15, 30, 60, and 120 min thereafter.

Results: The data of 62 subjects in the ketamine group and 64 patients in the ketorolac group were analyzed. The mean age of the patients was $34.2 \pm 9.9$ and $37.9 \pm 10.6$ years in the ketamine and ketorolac group, respectively. There was no significant difference in the mean NRS scores at each time point, except for the 5 min, between the two groups. Despite a marked decrease in pain severity in the ketamine group from drug administration at the $5 \mathrm{~min}$, a slight increase in pain was observed from the 5 min to the $15 \mathrm{~min}$. The rate of adverse drug reactions, including dizziness $(P=0.001)$, agitation $(P=0.002)$, increased systolic blood pressure $(>140 \mathrm{mmHg}$ ), and diastolic blood pressure $(>90 \mathrm{mmHg}$ ) was higher in the ketamine group.

Conclusions: Low dose ketamine is as effective as ketorolac in pain management in patients with renal colic presenting to the ED. However, it is associated with a higher rate of adverse drug reactions. (Korean J Pain 2019; 32: 97-104)

Key Words: Acute pain; Blood pressure; Double-blind method; Drug-related adverse reactions; Hospital emergency service; Ketamine; Ketorolac; Pain management; Randomized controlled trial; Renal colic; Urinary calculi.

Received December 18, 2018. Revised January 16, 2019. Accepted January 23, 2019.

Correspondence to: Mozhgan Farmahini-Farahani

Department of Emergency Medicine, Sina Hospital, Hasanabad Square, Tehran 1136746911, Iran

Tel: +98-91-2680-6154, Fax: +98-21-6312-1432, E-mail: farahanimozhgan@yahoo.com

ORCID: https://orcid.org/0000-0001-7529-6617

() This is an open-access article distributed under the terms of the Creative Commons Attribution Non-Commercial License (http:// creativecommons.org/licenses/by-nc/4.0/), which permits unrestricted non-commercial use, distribution, and reproduction in any medium, provided the original work is properly cited.

(c) The Korean Pain Society, 2019 


\section{INTRODUCTION}

Urinary stone pain, also known as renal colic, is one of the most frequent causes of emergency department (ED) visits. Renal colic is the most common manifestation of urinary stones, which is very excruciating [1]. Renal stones usually cause a very severe colicky pain. It is reported that it affects about $1 \%-5 \%$ of the population in developed countries, inflicting pain on about 2.1 million individuals every year. Renal stones affect about $5 \%-12 \%$ of the people in industrial societies at least once in their lifetime and may relapse in about $50 \%$ of the patients [2-4]. Effective and prompt pain management is one of the priorities and the basis of treatment in patients presenting to ED with renal colic. Since more than $90 \%$ of the stones are expelled spontaneously, the best approach with these patients is to manage their pain [5-8].

Opioids and non-steroidal anti-inflammatory drugs (NSAIDs) are widely used for pain management of these patients in the ED; however, their administration is associated with side effects and limitations [9-16]. NSAIDs, like ketorolac, are the drug of choice for pain management of patients with renal colic. Intravenous (IV) administration of these drugs has a better and faster effect compared to intramuscular (IM) injection or oral use. However, these drugs should be administered with caution in patients at risk of gastrointestinal bleeding, and those with underlying renal problems. Moreover, NSAIDs may cause a delay in lithotripsy due to inducing platelet function disorders $[17,18]$.

Several studies are investigating the use of other drugs in patients worldwide [19-21]. IV ketamine is a rather safe analgesic compared to opioids, but its effectiveness in renal colic has not been investigated extensively. Ketamine binds to $\mathrm{N}$-methyl-D-aspartate (NMDA) receptors in the posterior horn of the spinal cord and blocks the transmission of painful stimuli. It is also used as a pre-intubation drug in asthmatic patients, due to its relaxing effect on smooth muscles, and has analgesic and anxiolytic effects at the time of injection [22-25]. Ketamine can be administered IV, IM, orally, buccally, epidurally, nasally, and subcutaneously [22,26]. A review of its applications suggests that it may also be used in renal colic because management of pain and anxiety in these patients, together with the occurrence of smooth muscle spasms, may resolve the symptoms. However, the use of ketamine is al- so associated with different side effects, including tachycardia, increased blood pressure, and emergence phenomena following its administration [23,27,28]. Using a low dose of a drug to minimize its side effects has always been a matter of debate. Several studies have shown that lowdose ketamine, administered orally, is effective in reducing acute pain, but no study has investigated its effectiveness in management of renal colic [26,29,30].

The authors of the current study believe that administration of low-dose ketamine may be useful in avoiding its side effects. Therefore, this study was conducted to compare the effect of low-dose IV ketamine versus IV ketorolac in acute pain management of renal colic in an emergency setting.

\section{MATERIALS AND METHODS}

\section{Study design}

This double-blind randomized clinical trial was conducted from 1 March 2016 to 30 February 2017 in Imam Khomeini Hospital Complex and Sina Hospital, Tehran, Iran. The Ethics Committee of Tehran University of Medical Sciences approved the protocol of the study (approval number: IR.TUMS.REC.1394.786), and the study was registered in the Iranian Registry of Clinical Trials at www.irct.ir (registration code: IRCT2017021932660N1). This trial was carried out in accordance with the tenets of the Declaration of Helsinki. The objective and protocol of the study were explained to the subjects who met the inclusion criteria in simple language and their informed consent was obtained in writing if they were willing to join the study. Participation in this research caused no disorder in diagnostic and therapeutic procedures and no additional costs were imposed on the patients.

\section{Study population}

Patients over 18 years of age who presented to the ED with acute renal colic and clinical symptoms suggesting renal stones, as well as patients with a history of renal calculus, whose symptoms were similar to previous attacks, were included in this study. The exclusion criteria were sensitivity to ketamine or ketorolac, ischemic heart disease, hypertension, intracerebral vascular abnormalities, fibromyalgia, chronic pains managed with morphine, use of 
analgesics within $4 \mathrm{~h}$ before presenting to the ED, pregnancy, lactation, renal or hepatic failure, psychosis, trauma to the head or eye, and unstable vital signs. An emergency medicine specialist evaluated the physical examinations and past medical histories of the patients to determine the presence of the above criteria.

According to $\alpha=0.05$ and $\beta=0.9,63$ patients were required in each group to detect any significant difference in pain between the two groups (a total of 126 patients). The patients who met the inclusion and exclusion criteria were randomly assigned to one of two groups: either lowdose IV ketamine (group A) or IV ketorolac (group B), using a computer-generated random numbers table. Fig. 1 presents the CONSORT flowchart of the patients.

\section{Intervention}

The baseline data and demographic characteristics of the patients were recorded in predesigned checklists. Before drug administration, one of the researchers assessed the initial pain severity using the numerical rating scale (NRS). Then, ketamine at a dose of $0.6 \mathrm{mg} / \mathrm{kg}$ or ketorolac at a dose of $30 \mathrm{mg}$ was administered by another person/nurse. In the next step, the same researcher who initially as- sessed the pain, re-assessed pain severity using the NRS and the rate of adverse drug reactions at 5, 15, 30, 60, and $120 \mathrm{~min}$ after drug administration. The investigator, who was responsible for pain assessment, was kept blinded to the type of the administered drug. If pain was intolerable despite administration of ketorolac or ketamine, morphine was injected at a dose of $0.1 \mathrm{mg} / \mathrm{kg}$ as a rescue medicine. Lack of effective pain management within 120 min of two ketamine injections at a dose of $0.6 \mathrm{mg} / \mathrm{kg}$ and an NRS score above 5 indicated treatment failure [31].

\section{Statistical analysis}

A chi-square and Fisher exact test were applied to analyze qualitative data, and the independent $t$-test and MannWhitney tests were used to compare quantitative variables between case and control groups. The Friedman test was administered to analyze pain changes over time. Qualitative data are presented as frequency and percentage, and quantitative data are reported as mean, median, standard deviation, and interquartile range. The Kolmogorov-Smirnov test and $\mathrm{Q}-\mathrm{Q}$ plot were applied to assess data normality. Data were analyzed with IBM SPSS ver. 22 (IBM Corp., Armonk, NY) and $P<0.05$ was considered significant.

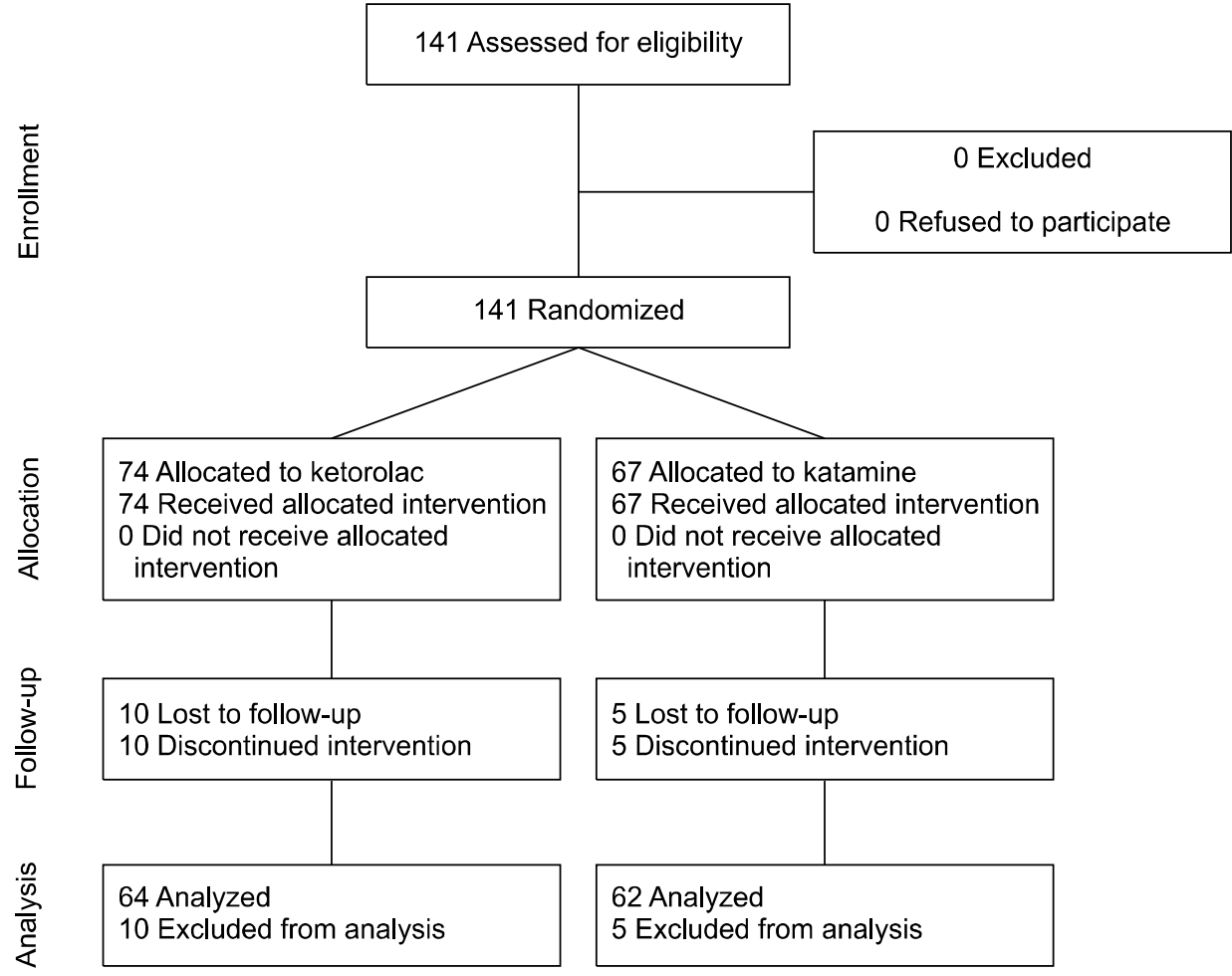

Fig. 1. CONSORT flowchart of the patients. 


\section{RESULTS}

The data of the 62 patients in the ketamine group and 64 subjects in the ketorolac group were analyzed. The mean age of the patients was $34.2 \pm 9.9$ and $37.9 \pm 10.6$ years in ketamine and ketorolac groups, respectively $(P=0.092)$. Moreover, there was no significant difference in age categories between the two groups (Table 1).

\section{Pain assessment}

There was no significant difference in the mean NRS scores at different time points, except for the $5 \mathrm{~min}$, between the two groups $(P>0.05)$ (Table 2). Despite a substantial decrease in pain severity from injection to the 5 min in the ketamine group, a slight increase was reported from $\min 5$ to $\min 15$. Moreover, in patients receiving ket-

Table 1. Baseline Characteristics of Studied Patients with Renal Colic in Current Study

\begin{tabular}{lrrr}
\hline \multicolumn{1}{c}{ Characteristic } & $\begin{array}{l}\text { Ketamine } \\
(n=62)\end{array}$ & $\begin{array}{l}\text { Ketorolac } \\
(n=64)\end{array}$ & $P$ value \\
\hline $\begin{array}{l}\text { Sex } \\
\text { Male }\end{array}$ & $44(71.0)$ & $52(81.2)$ & 0.175 \\
$\quad \begin{array}{l}\text { Female } \\
\text { Age }(y)\end{array}$ & $18(29.0)$ & $12(18.8)$ & \\
$\leq 30$ & $31(50.0)$ & $18(28.1)$ & \\
$\quad 31-40$ & $15(24.2)$ & $19(29.7)$ & \\
$41-50$ & $12(19.4)$ & $18(28.1)$ & \\
$>50$ & $4(6.5)$ & $9(14.1)$ & \\
History of renal stone & & & 0.367 \\
Yes & $51(82.3)$ & $48(75.0)$ & \\
No & $11(17.7)$ & $16(25.0)$ & \\
\hline
\end{tabular}

Values are presented as number (\%). amine, the pain severity decreased by 4 points from injection to $15 \mathrm{~min}$, compared to the initial pain severity, while the pain severity never decreased by 3 points compared to the previous time point in the ketorolac group; however, the pain score was 2 at $30 \mathrm{~min}$ in patients receiving ketorolac. The pain severity decreased significantly in both groups over time $(P<0.001)$ (Fig. 2).

\section{Side effects}

A significant difference was observed in the mean systolic blood pressure and heart rate at 5,15 , and 30 min between the two groups $(P<0.05)$ (Fig. 3). Total side effects were reported in 39 patients (62.9\%) in the ketamine group and 9 patients (14.1\%) in the ketorolac group. The rate of side effects was significantly higher in the ketamine group $(P$ $=0.001)$. Details of reported side effects were summarized

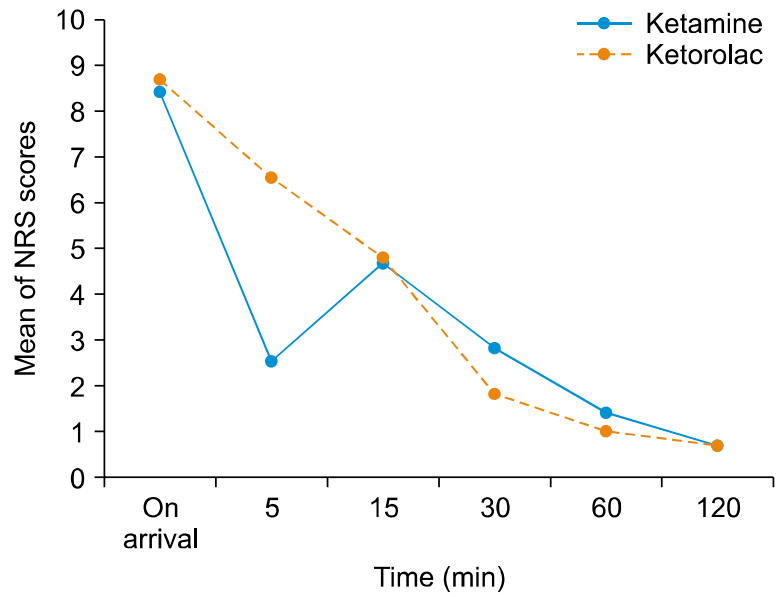

Fig. 2. Changes of pain severity in patients receiving ketorolac and ketamine during the study period. NRS: numerical rating scale.

Table 2. Pain Score of Subjects at Different Time Intervals Based on Numerical Rating Scale

\begin{tabular}{|c|c|c|c|c|c|}
\hline \multirow{2}{*}{ Time (min) } & \multicolumn{2}{|c|}{ Ketamine $(n=62)$} & \multicolumn{2}{|c|}{ Ketorolac $(n=64)$} & \multirow{2}{*}{$P$ value } \\
\hline & Mean \pm SD & Median (IQR) & Mean \pm SD & Median (IQR) & \\
\hline On arrival & $8.4 \pm 1.5$ & $8.0(3.0)$ & $8.7 \pm 1.4$ & $8.0(2.0)$ & 0.217 \\
\hline 5 & $2.5 \pm 2.7$ & $3.0(5.0)$ & $6.5 \pm 2.1$ & $6.0(3.0)$ & $<0.001$ \\
\hline 15 & $4.7 \pm 3.1$ & $5.0(4.0)$ & $4.8 \pm 2.5$ & $5.0(3.0)$ & 0.998 \\
\hline 30 & $2.8 \pm 2.9$ & $3.0(5.0)$ & $1.8 \pm 2.3$ & $0.0(4.5)$ & 0.072 \\
\hline 60 & $1.4 \pm 2.4$ & $0.0(3.0)$ & $1.0 \pm 2.2$ & $0.0(0.8)$ & 0.476 \\
\hline 120 & $0.7 \pm 1.9$ & $0.0(0.0)$ & $0.7 \pm 1.6$ & $0.0(0.0)$ & 0.591 \\
\hline
\end{tabular}

SD: standard deviation, IQR: interquartile range. 
A

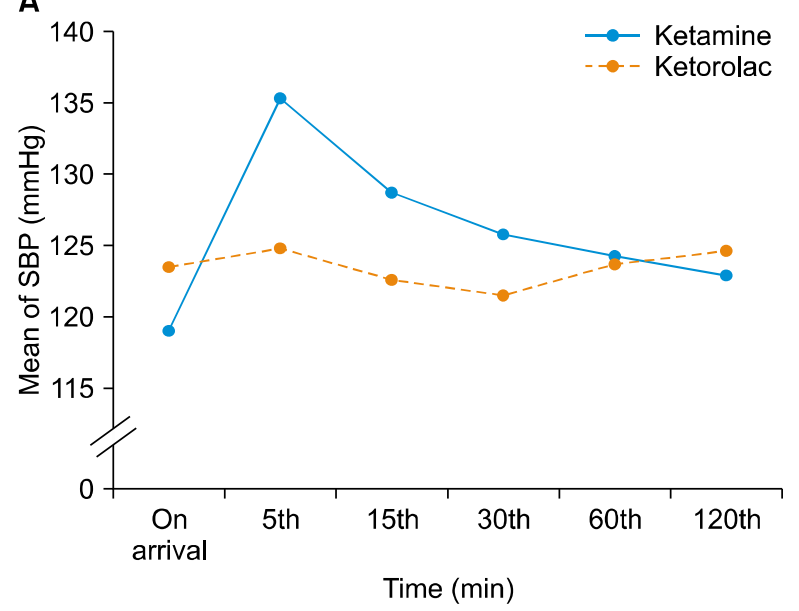

B

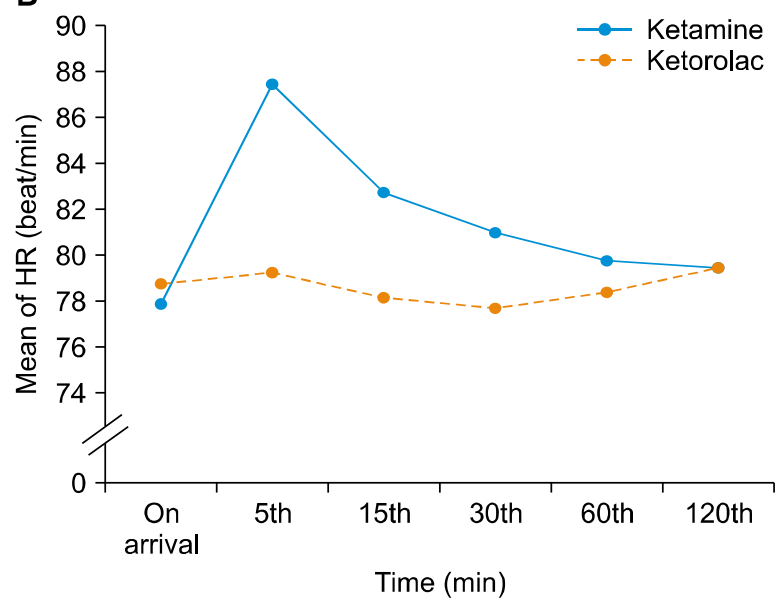

Fig. 3. Vital signs changes in patients receiving ketorolac and ketamine during the study period. Mean of (A) systolic blood pressure (SBP) and (B) heart rate (HR).

Table 3. Frequency of Side Effects in the Study Population

\begin{tabular}{lrcr}
\hline \multicolumn{1}{c}{ Side effect } & $\begin{array}{r}\text { Ketamine } \\
(n=62)\end{array}$ & $\begin{array}{c}\text { Ketorolac } \\
(n=64)\end{array}$ & $P$ value \\
\hline Tachycardia & $2(3.2)$ & 0 & 0.240 \\
Blood pressure rising & $15(27.8)$ & $1(1.9)$ & $<0.001$ \\
Nausea & $7(11.3)$ & $9(14.1)$ & 0.640 \\
Dizziness & $25(40.3)$ & 0 & $<0.001$ \\
Agitation & $9(14.5)$ & 0 & 0.002 \\
Other & $7(11.3)$ & 0 & 0.006 \\
\hline
\end{tabular}

Values are presented as number (\%).

in Table 3.

\section{DISCUSSION}

This study was done to compare low-dose ketamine versus IV ketorolac in acute pain management of patients with renal colic presenting to the ED. According to the results of this study, low-dose ketamine was as effective as IV ketorolac in pain management of these patients, but its use was associated with a higher rate of side effects. In the present study, ketamine and ketorolac were equally effective in controlling pain severity but the occurrence of complications like tachycardia, increased blood pressure, dizziness, and agitation was higher following ketamine administration.

Sadove et al. [32] was one of the first researchers who proposed the analgesic effects of ketamine at subdisso- ciative low doses. However, after several years, the effectiveness of ketamine as an analgesic is still a matter of debate and discussion. Some researchers believe that its antihyperalgesic effects are stronger than its analgesic properties, and a number of studies are being conducted in this regard [24,33]. Few studies have investigated the effect of ketamine on pain management of patients with renal colic, although its effects in other study populations have been more frequently studied. Some previous investigations have shown that ketamine is as effective as opium in post-surgical pain management. Moreover, it has proved very effective in burn patients [24]. The results of a study by Galinski et al. [34] on the management of acute pain in trauma patients showed that administration of lowdose ketamine and morphine reduced the need for morphine by about $26 \%$ for $30 \mathrm{~min}$. Moreover, Bespalov et al. [35] reported that blockade of NMDA receptors by ketamine inhibits hyperalgesia and prolongs the duration of the antinociceptive effect of opioids. Some other studies have claimed that intranasal ketamine may be as effective as IV morphine in pain management of renal colic patients [36]. However, some studies have reported contradictory results. For example, Vosoughin et al. [37] reported that NSAIDs were more effective than ketamine in women undergoing elective gynecologic laparoscopy.

Ketamine exerts its analgesic effects through different mechanisms, including NMDA receptor antagonism, opioid receptor agonism, sigma receptor interaction, local anesthetic action, cholinergic effects, monoamine effects, and 
supraspinal mechanisms [24]. It is obvious that these mechanisms are associated with different clinical manifestations that can be desirable or undesirable [38]; for example, unlike NSAIDs, ketamine does not induce platelet function disorders [39]. Moreover, it plays an undeniable role in patients with opioid tolerance [40]. In addition, it may be a proper alternative in asthmatic patients in whom histamine release induced by morphine is a problem. One of the advantages of ketamine is its diverse administration routes [24]; for example, Andolfatto et al. [41] studied the analgesic effect of intranasal ketamine in the ED.

In the present study, the frequency of side effects, including dizziness, and increased systolic blood pressure and diastolic blood pressure (>90 $\mathrm{mmHg}$ ), was higher in the ketamine group. Physicians are not willing to prescribe ketamine because it induces agitation and dissociation $[36,37]$. The threshold of consciousness impairment following ketamine administration is very low and loss of consciousness is reported even at a dose of $0.25 \mathrm{mg} / \mathrm{kg}$. It is recommended to administer titrated doses of ketamine starting from $0.1 \mathrm{mg} / \mathrm{kg}$ to a maximum of $0.5 \mathrm{mg} / \mathrm{kg}$ $[24,42]$. Tachycardia and increased blood pressure are other side effects of ketamine that require attention despite being transient [43].

The most common limitations of objective studies are diversity in subjective responses regarding pain perception and encouraging the patients to participate in the study. The patient's perception of pain is extensively affected by the drug's pharmacogenetics and is different from time to time. Another limitation of the study was adverse drug reactions, including disorientation in time and place, dissociative disorders, and hallucination; however, it seems that IV administration of low-dose ketamine is not associated with psychotomimetic effects or adverse pharmacologic reactions. More studies are required to assess whether ketamine has long-terms benefits in decreasing the occurrence or severity of the pain. Moreover, the stone size and location and the level of hydronephrosis, which were not investigated in this study, may affect interpretation of the results. As another limitation, emergency revisits and the outcomes of these patients were not evaluated, either.

According to the results of the present study, lowdose ketamine is as effective as IV ketorolac in pain management of IV renal colic patients presenting to the ED, but its use is associated with a higher rate of side effects. The advantages and disadvantages of ketamine admin- istration in comparison with ketorolac should be studied and discussed to determine its indications. As of now, there is no justification for using ketamine instead of ketorolac as a first line of treatment in patients with renal colic in the emergency setting. However, ketamine may be administered as an alternative when ketorolac is contraindicated.

A published systematic review conducted by Ghate et al. [44] in 2017 reported that there is broad variation in the dose and route of low dose ketamine used in previous studies ranging from 0.1 to $0.7 \mathrm{mg} / \mathrm{kg}$ administered subcutaneously, intravenously, or intramuscularly. It seems that determination of the exact sub-dissociative dose of ketamine still requires further investigations, so reducing the side effects but benefit from advantages.

\section{ACKNOWLEDGEMENTS}

We would like to thank emergency medicine department staff of Sina and Imam Khomeini Hospitals who helped in management of these patients. The present article was extracted from the thesis of Dr. Mozhgan FarmahiniFarahani to achieve her specialist degree in emergency medicine from Tehran University of Medical Sciences.

\section{CONFLICT OF INTEREST}

No potential conflict of interest relevant to this article was reported.

\section{REFERENCES}

1. Teichman JM. Clinical practice: acute renal colic from ureteral calculus. N Engl J Med 2004; 350: 684-93.

2. Romero V, Akpinar H, Assimos DG. Kidney stones: a global picture of prevalence, incidence, and associated risk factors. Rev Urol 2010; 12: e86-96.

3. Brown J. Diagnostic and treatment patterns for renal colic in US emergency departments. Int Urol Nephrol 2006; 38: 8792.

4. Zabihi N, Teichman JM. Dealing with the pain of renal colic. Lancet 2001; 358: 437-8.

5. Engeler DS, Schmid S, Schmid HP. The ideal analgesic treatment for acute renal colic: theory and practice. Scand J Urol Nephrol 2008; 42: 137-42.

6. Bounes V, Vallé B, Concina F, Lauque D, Ducassé JL, Edlow JA. Treatment of acute renal colic in Us and French EDs: simulated cases and real cases in acute pain management. 
Am J Emerg Med 2016; 34: 1955-8.

7. Shin MT, Juho YC, Meng E, Sun GH, Cha TL, Wu ST, et al. Pain severity in renal colic: a retrospective evaluation of initial visits in patients at a medical center. Int Surg J 2016; 3: 480-3.

8. Janati M, Kariman H, Memary E, Davarinezhad-Moghadam E, Arhami-Dolatabadi A. Educational intervention effect on pain management quality in emergency department; a clinical audit. Adv J Emerg Med 2018; 2: e16.

9. Miller NL, Lingeman JE. Management of kidney stones. BMJ 2007; 334: 468-72.

10. Knoedler JJ, Lieske JC. Non-steroidal anti-inflammatory drugs for renal colic. Lancet 2016; 387: 1971-2.

11. Bultitude M, Rees J. Management of renal colic. BMJ 2012; 345: e5499.

12. Benyamin R, Trescot AM, Datta S, Buenaventura R, Adlaka $\mathrm{R}$, Sehgal N, et al. Opioid complications and side effects. Pain Physician 2008; 11 (2 Suppl): S105-20.

13. Baratloo A, Amiri M, Forouzanfar MM, Hasani S, Fouda S, Negida A. Efficacy measurement of ketorolac in reducing the severity of headache. J Emerg Pract Trauma 2016; 2: $21-4$.

14. Alimohammadi $H$, Baratloo A, Abdalvand A, Rouhipour A, Safari S. Effects of pain relief on arterial blood o2 saturation. Trauma Mon 2014; 19: e14034.

15. Edwards JM, Sloan EP, Eder S, Chan S. Renal colic patient pain management in the emergency department. Ann Emerg Med 2004; 44(4 Suppl): S58.

16. Abdolrazaghnejad A, Banaie M, Tavakoli N, Safdari M, Rajabpour-Sanati A. Pain management in the emergency department: a review article on options and methods. Adv J Emerg Med 2018; 2: e45.

17. Tramèr MR, Williams JE, Carroll D, Wiffen PJ, Moore RA, McQuay HJ. Comparing analgesic efficacy of non-steroidal anti-inflammatory drugs given by different routes in acute and chronic pain: a qualitative systematic review. Acta Anaesthesiol Scand 1998; 42: 71-9.

18. Manthey DE, Nicks BA. Urologic stone disease. In: Tintinalli's emergency medicine: a comprehensive study guide. 8th ed. Edited by Tintinalli JE, Stapczynski JS, Ma OJ, Yealy DM, Meckler GD, Cline DM. New York, McGraw-Hill. 2016, pp 609-13.

19. Jackson J, Farhi J, Wheeler K, Rueb G, Thom C, Schenkman $N$. Retrospective review of acute renal colic management in the emergency department and review of guidelines. Urol Pract 2018; 5: 113-9.

20. Arhami Dolatabadi A, Memary E, Kariman H, Nasiri Gigloo K, Baratloo A. Intranasal desmopressin compared with intravenous ketorolac for pain management of patients with renal colic referring to the emergency department: a randomized clinical trial. Anesth Pain Med 2017; 7: e43595.

21. Holdgate A, Pollock T. Systematic review of the relative efficacy of non-steroidal anti-inflammatory drugs and opioids in the treatment of acute renal colic. BMJ 2004; 328: 1401.

22. Svenson JE, Abernathy MK. Ketamine for prehospital use: new look at an old drug. Am J Emerg Med 2007; 25: 977-80.

23. Morgan CJ, Curran HV; Independent Scientific Committee on Drugs. Ketamine use: a review. Addiction 2012; 107 : 2738.

24. Persson J. Ketamine in pain management. CNS Neurosci Ther 2013; 19: 396-402.

25. Mohammadshahi A, Abdolrazaghnejad A, Nikzamir H, Safaie A. Intranasal ketamine administration for narcotic dose decrement in patients suffering from acute limb trauma in emergency department: a double-blind randomized placebocontrolled trial. Adv J Emerg Med 2018; 2: e30.

26. Pasero C, McCaffery M. Pain control: ketamine: low doses may provide relief for some painful conditions. Am J Nurs 2005; 105: 60-4.

27. Weisz K, Bajaj L, Deakyne SJ, Brou L, Brent A, Wathen J, et al. Adverse events during a randomized trial of ketamine versus co-administration of ketamine and propofol for procedural sedation in a pediatric emergency department. $J$ Emerg Med 2017; 53: 1-9.

28. Treston G, Bell A, Cardwell R, Fincher G, Chand D, Cashion $G$. What is the nature of the emergence phenomenon when using intravenous or intramuscular ketamine for paediatric procedural sedation? Emerg Med Australas 2009; 21 : 31522.

29. Huge V, Lauchart M, Magerl W, Schelling G, Beyer A, Thieme D, et al. Effects of low-dose intranasal (S)-ketamine in patients with neuropathic pain. Eur J Pain 2010; 14: 387-94.

30. Bilgen S, Köner O, Türe H, Menda F, Fiçicioğlu C, Aykaç B. Effect of three different doses of ketamine prior to general anaesthesia on postoperative pain following Caesarean delivery: a prospective randomized study. Minerva Anestesiol 2012; 78: 442-9.

31. Loeser JD, Melzack R. Pain: an overview. Lancet 1999; 353: 1607-9.

32. Sadove MS, Shulman M, Hatano S, Fevold N. Analgesic effects of ketamine administered in subdissociative doses. Anesth Analg 1971; 50: 452-7.

33. Visser E, Schug SA. The role of ketamine in pain management. Biomed Pharmacother 2006; 60: 341-8.

34. Galinski M, Dolveck F, Combes X, Limoges V, Smaïl N, Pommier $V$, et al. Management of severe acute pain in emergency settings: ketamine reduces morphine consumption. Am J Emerg Med 2007; 25: 385-90.

35. Bespalov AY, Zvartau EE, Beardsley PM. Opioid-NMDA receptor interactions may clarify conditioned (associative) components of opioid analgesic tolerance. Neurosci Biobehav Rev 2001; 25: 343-53. 
36. Farnia MR, Jalali A, Vahidi E, Momeni M, Seyedhosseini J, Saeedi M. Comparison of intranasal ketamine versus IV morphine in reducing pain in patients with renal colic. Am J Emerg Med 2017; 35: 434-7.

37. Vosoughin M, Mohammadi S, Dabbagh A. Intravenous ketamine compared with diclofenac suppository in suppressing acute postoperative pain in women undergoing gynecologic laparoscopy. J Anesth 2012; 26: 732-7.

38. Assouline B, Tramèr MR, Kreienbühl L, Elia N. Benefit and harm of adding ketamine to an opioid in a patient-controlled analgesia device for the control of postoperative pain: systematic review and meta-analyses of randomized controlled trials with trial sequential analyses. Pain 2016; 157 : 2854-64.

39. Holinstat M. Normal platelet function. Cancer Metastasis Rev 2017; 36: 195-8.
40. Tawfic QA. A review of the use of ketamine in pain management. J Opioid Manag 2013; 9: 379-88.

41. Andolfatto G, Willman E, Joo D, Miller P, Wong WB, Koehn $M$, et al. Intranasal ketamine for analgesia in the emergency department: a prospective observational series. Acad Emerg Med 2013; 20: 1050-4.

42. Wedmore IS, Johnson T, Czarnik J, Hendrix S. Pain management in the wilderness and operational setting. Emerg Med Clin North Am 2005; 23: 585-601, xi-xii.

43. Allen CA, Ivester JR Jr. Ketamine for pain management-side effects \& potential adverse events. Pain Manag Nurs 2017; 18: $372-7$.

44. Ghate G, Clark E, Vaillancourt C. Systematic review of the use of low-dose ketamine for analgesia in the emergency department. CJEM 2018; 20: 36-45. 